\title{
Influence of Environmental Factors on Severity of Citrus Scab and Melanose
}

\author{
J. P. Agostini, Research Plant Pathologist, Instituto Naciónal de Técnologia Agropecúaria, 3384 Montecarlo, \\ Misiones, Argentina; and P. M. Bushong, former Senior Biological Scientist, Alka Bhatia, Senior Biological Sci- \\ entist, and L. W. Timmer, Professor, University of Florida, IFAS, Citrus Research and Education Center and De- \\ partment of Plant Pathology, Lake Alfred 33850
}

\begin{abstract}
Agostini, J. P., Bushong, P. M., Bhatia, A., and Timmer, L. W. 2003. Influence of environmental factors on severity of citrus scab and melanose. Plant Dis. 87:1102-1106.

Citrus scab, caused by Elsinoe fawcettii, and melanose, caused by Diaporthe citri, produce external blemishes on citrus fruit, reducing acceptability of the fruit for the fresh market. In laboratory studies, rough lemon seedlings and grapefruit seedlings were inoculated with conidia of $E$. fawcettii and D. citri, respectively, and exposed to a range of temperatures and durations of leaf wetness. Scab was most severe at temperatures from 23.5 to $27^{\circ} \mathrm{C}$ and much less severe at $17,20,30$, or $32^{\circ} \mathrm{C}$. A leaf wetness duration of $4 \mathrm{~h}$ was sufficient for some infection, but $12 \mathrm{~h}$ of leaf wetness were needed for maximum infection with scab. Melanose was equally severe at 24 and $28^{\circ} \mathrm{C}$, moderate at $20^{\circ} \mathrm{C}$, and low at $32^{\circ} \mathrm{C}$. Melanose infection was minimal with $4 \mathrm{~h}$ of leaf wetness, moderate with 8 to $16 \mathrm{~h}$, and reached maximum levels at $24 \mathrm{~h}$ or more of leaf wetness. In field studies, grapefruit seedlings with new shoots were placed beneath trees weekly, and disease severity was evaluated in relation to environmental factors. Melanose severity increased sharply with an increase in total weekly rainfall, leaf wetness durations of greater than $80 \mathrm{~h}$ per week, and average temperatures above $22^{\circ} \mathrm{C}$.
\end{abstract}

Citrus scab is caused by Elsinoe fawcettii Bitancourt \& Jenk. (anamorph Sphaceloma fawcettii Jenk.), and melanose is caused by Diaporthe citri F.A. Wolf (anamorph Phomopsis citri H. Fawc. Non (Sacc.) Traverso \& Spessa) $(7,12)$. Both diseases affect young leaves, twigs, and fruit. Scab and melanose generally do not affect yield but have serious effects on the external appearance of fruit and thus on the utilization of fruit for the fresh market. In Florida, scab affects grapefruit, many tangerines and their hybrids, and lemons. Melanose affects all types of citrus, but is most important on grapefruit destined for the fresh market. Scab and melanose are two of the most important diseases that must be controlled on fresh-market fruit. A $10 \%$ reduction in fresh market fruit was estimated to reduce the profitability of grapefruit production in Florida by $\$ 866$ per hectare (8).

Inoculum for citrus scab consists of hyaline and spindle-shaped conidia that are produced on the surface of scab pustules on leaves, twigs, or fruit (4). Only very

Corresponding author: L. W. Timmer

E-mail: 1wt@lal.ufl.edu

This research was supported by the Florida Agricultural Experiment Station and approved for publication as Journal Series No. R-09222.

Accepted for publication 22 April 2003.

Publication no. D-2003-0623-02R

(C) 2003 The American Phytopathological Society young tissues are susceptible to infection. Leaves can be infected until they are halfexpanded, and fruit can be infected for about 6 to 8 weeks after petal fall (4). Fawcett (1) found that growth of E. fawcettii was greatest at $21^{\circ} \mathrm{C}$, and sporulation on sour orange leaves was optimal at 21 to $27^{\circ} \mathrm{C}$. Infection of sour orange leaves occurred only at temperatures below $23^{\circ} \mathrm{C}$. In contrast, Whiteside (10) found that the optimum temperature for infection of leaves of rough lemon was 24 to $28^{\circ} \mathrm{C}$. The minimal wetting period for infection was 2.5 to $3.5 \mathrm{~h}$ at optimum temperature. The maximum number of lesions was observed after $7 \mathrm{~h}$ of wetting, the longest duration tested.

Most of the inoculum with melanose consists of conidia of $P$. citri produced on dead twigs in the canopy $(11,12)$. Conidia are washed down over fruit, leaves, and twigs by rain. Fruit are susceptible for at least 3 months after petal fall, and leaves are susceptible until they are mature. Kuramoto and Yamada (3) found that conidia germinate in $6 \mathrm{~h}$ at $16^{\circ} \mathrm{C}$ and in $4 \mathrm{~h}$ at 20 to $28^{\circ} \mathrm{C}$. They found that infection of mandarin leaves occurred in $8 \mathrm{~h}$ at 24 to $28^{\circ} \mathrm{C}$, in $12 \mathrm{~h}$ at $20^{\circ} \mathrm{C}$, and in $16 \mathrm{~h}$ at $16^{\circ} \mathrm{C}$. Ushiyama (9) found that conidia germinated and infected satsuma mandarin leaves in $4 \mathrm{~h}$ at 25 or $34^{\circ} \mathrm{C}$ but took $6 \mathrm{~h}$ at $20^{\circ} \mathrm{C}$. Symptoms appeared in 3 days at $20^{\circ} \mathrm{C}$ and 4 days at $30^{\circ} \mathrm{C}$. Homma and Yamada (2) found that infection of satsuma mandarin fruit required $12 \mathrm{~h}$ of wetness at $25^{\circ} \mathrm{C}$ and $72 \mathrm{~h}$ at $10^{\circ} \mathrm{C}$. In Texas, melanose infection was associated primarily with prolonged rainy periods in June and July $(5,7)$, although specific conditions for infection were not investigated in those studies.

The information available on the relationship of leaf wetness and temperature with infection of citrus by E. fawcettii is contradictory $(1,10)$. In addition, leaf wetness durations beyond $7 \mathrm{~h}$ have not been evaluated for their effect on severity of scab. More information on the relationship of temperature and leaf wetness with disease severity is available for melanose $(2,3,9)$. However, most of these studies were conducted in Japan on mandarins. Temperatures in citrus-growing areas in Florida are warmer than in Japan, and isolates of the pathogen may adapt to local conditions. This study was undertaken to determine the relationship between temperature, duration of leaf wetness, and severity of citrus scab and melanose under controlled conditions in the laboratory. Field studies were also conducted to relate the effects of rainfall, temperature, and leaf wetness on severity of melanose using trap plants under conditions in central Florida.

\section{MATERIALS AND METHODS}

Plant materials. Potted seedlings of rough lemon (Citrus jambhiri Lush.), which are highly susceptible to all pathotypes of E. fawcettii (6), were used to examine the effects of temperature and leaf wetness duration on severity of scab. Seedlings of grapefruit (C. paradisi Macfad.), which are highly susceptible to $D$. citri, were used to examine the effects of temperature and leaf wetness duration on severity of melanose. For the laboratory studies, seedlings were grown in soilless potting mix in large containers $(25 \mathrm{~cm}$ tall $\times 10 \mathrm{~cm}$ diameter; Stuewe \& Sons, Corvallis, OR) in the greenhouse to a height of 30 to $50 \mathrm{~cm}$. Plants were then pruned back to a height of about $15 \mathrm{~cm}$ to force growth of new shoots. Two to four shoots of uniform length and leaf maturity were selected per plant, and all other foliage was removed. Grapefruit seedlings used as trap plants in the field were grown in soilless potting mix in 2.5-liter pots in the greenhouse. Plants were grown as a single stem to a height of at least $1.0 \mathrm{~m}$, then pruned back to $0.5 \mathrm{~m}$ to force new growth. Three to four shoots of uniform maturity were selected on each plant and the remainder of the foliage removed prior to placement in the field. 
Laboratory leaf wetness and temperature studies. Citrus scab inoculum preparation. Isolates R-34 and R-36 of E. fawcettii originally isolated from Temple tangor (Citrus sinensis (L.) Osbeck $\times C$. reticulata Blanco) near Lake Placid, FL, were used for all citrus scab studies. Both isolates are of the Florida Broad Host Range pathotype (6) and are highly pathogenic to rough lemon. Inoculum was prepared as described by Whiteside (10) by first removing a $1 \mathrm{~mm}^{2}$ piece of mycelium from an actively growing culture of $E$. fawcettii on potato dextrose agar (PDA) and crushing it with a sterile spatula in an empty petri dish. Liquid Fries medium was poured into the dish, and the mycelial fragments were stirred into the medium. Dishes were incubated in the dark at room temperature $\left(23\right.$ to $\left.25^{\circ} \mathrm{C}\right)$ for $48 \mathrm{~h}$. The liquid medium was then decanted, leaving microcolonies attached to the base of the dish. The colonies were washed three times with sterile distilled water, covered with autoclaved lake water, and incubated for 24 $\mathrm{h}$ in the dark for conidia production. Conidia in the lake water were added to sterile distilled water and the concentration adjusted to about $10^{5}$ conidia per ml.

Melanose inoculum preparation. Isolate S-22 of D. citri, obtained from G. E. Brown (Florida Department of Citrus, Lake Alfred), was used for all the melanose experiments. For pycnidia production, mature citrus twigs about 3 to 6 $\mathrm{mm}$ in diameter were cut into 5- to 7-cmlong segments and autoclaved. Three to four sterilized twigs were placed in each petri dish and partially covered with molten potato dextrose agar. Agar plugs with mycelia were transferred to plates, and the cultures were incubated for 30 to 45 days at $25^{\circ} \mathrm{C}$ for pycnidia production. Alternatively, PDA dishes were streaked with a conidial suspension of $P$. citri; pycnidia developed directly on the agar surface after 3 to 5 weeks of incubation at $27^{\circ} \mathrm{C}$. Conidia exuding from pycnidia were collected with a sterile needle and suspended in sterile distilled water. Conidia were washed three times by centrifugation to remove the mucilaginous slime that inhibits germination of conidia. The concentration was adjusted to $\approx 10^{5}$ conidia per $\mathrm{ml}$, and orange juice was added to a final concentration of $1 \%$ (vol/vol) as described by Whiteside (11).

Inoculations. For both scab and melanose, young shoots were inoculated with conidia using a chromatography sprayer (Crown Sprā Tool, North American Professional Products, Woodstock, IL). The inoculated plants were then covered individually with plastic bags and placed in incubators at the desired temperatures. Five plants were used for each temperature-leaf wetness combination. At desired times, the plants were removed from the incubator, the bags removed, and the plants transferred to the greenhouse for about 10 days for symptom development.
To measure severity of citrus scab, the number of lesions was counted on each leaf that was present at the time of inoculation, and severity was expressed as the number of lesions per leaf. To measure severity of melanose, each leaf present at the time of inoculation was rated on a scale of 0 to 4 , where $0=$ no lesions, $1=1$ to 10 lesions, $2=11$ to 100 lesions, $3=101$ to 1,000 lesions, and $4=$ confluent lesions. Results were expressed as the average rating for all inoculated leaves per plant.

Since the number of incubators and space within incubators were limited, a series of experiments was conducted with different temperature-leaf wetness combinations at various times. A total of $10 \mathrm{ex}-$ periments was conducted for citrus scab and 13 for melanose. Three to four temperatures and three to four wetting treatments were included in each experiment. Table 1 presents the number of experiments conducted for each temperature-leaf wetness duration combination. In each experiment, each replicate plant was bagged individually and placed within the incubator. After each selected leaf wetness duration period, five plants were removed at random from each incubator.

Data from the leaf wetness-temperature studies were subjected to analysis of variance using the mixed procedure in SAS (Version 8.2, SAS Institute, Cary, NC). In the analysis, temperature and leaf wetness were considered as fixed factors, and experiments were considered as a random factor. The Type III sum of squares was used, and mean squares were divided by the appropriate error term for each source of variation. Since trends among experiments were similar in most cases, data from different experiments were pooled for each disease.

Field studies. To assess the severity of melanose under environmental conditions typical of central Florida, trap plants were placed in the field for 1-week periods from mid-March 2001 to mid-March 2002. Six grapefruit seedlings with young leaves susceptible to melanose were placed beneath mature grapefruit trees severely affected by melanose. At the end of each week, plants were transferred to the greenhouse under dry conditions for symptom development. The severity of symptoms was evaluated on three leaves on each of three shoots, and a mean severity rating was calculated for each plant and for the six plants.

Weather data were collected by an automated station located within $500 \mathrm{~m}$ of the test site. The average temperature, total hours of leaf wetness, and total rainfall were calculated for each week. Leaf wetness data were not available for all weeks evaluated due to equipment failure. The relationship between environmental factors and melanose severity was determined using regression analyses, and the data were fitted to the most appropriate curves (Version 8.2, SAS). Multiple regression analyses were also conducted to combine all factors related to disease severity.

\section{RESULTS}

Laboratory leaf wetness-temperature studies. Citrus scab. The severity of citrus scab on leaves of rough lemon following

Table 1. Number of laboratory experiments conducted to evaluate severity of citrus scab and melanose on rough lemon and grapefruit seedlings, respectively, at different combinations of temperature and leaf wetness duration

\begin{tabular}{lccccccc}
\hline & & \multicolumn{7}{c}{ Leaf wetness duration (h) } \\
\cline { 3 - 7 } Disease & Temperature $\left({ }^{\circ} \mathbf{C}\right)$ & $\mathbf{4}$ & $\mathbf{8}$ & $\mathbf{1 2}$ & $\mathbf{1 6}$ & $\mathbf{2 4}$ & $\mathbf{4 8}$ \\
\hline Citrus scab & 17.0 & 2 & 3 & 3 & $\ldots{ }^{\mathrm{z}}$ & 3 & $\ldots$ \\
& 20.0 & 4 & 4 & 5 & $\ldots$ & 3 & $\ldots$ \\
& 23.5 & 5 & 5 & 4 & $\ldots$ & 4 & $\ldots$ \\
& 25.5 & 4 & 2 & 1 & $\ldots$ & 2 & $\ldots$ \\
Melanose & 27.0 & 4 & 4 & 4 & $\ldots$ & 4 & $\ldots$ \\
& 30.0 & 2 & 2 & 2 & $\ldots$ & 2 & $\ldots$ \\
& 32.0 & 3 & 4 & 3 & $\ldots$ & 3 & $\ldots$ \\
& 20.0 & 6 & 6 & 5 & 8 & 10 & 6 \\
& 24.0 & 7 & 7 & 6 & 6 & 8 & 3 \\
\end{tabular}

${ }^{\mathrm{z}}$ Not tested.

Table 2. Analysis of variance of the effect of temperature and duration of leaf wetness on the severity of citrus scab on rough lemon leaves inoculated in the laboratory with Elsinoe fawcettii

\begin{tabular}{lrrrc}
\hline Source of variation & df & MS & \multicolumn{1}{c}{$\boldsymbol{F}$} & $\boldsymbol{P}$ \\
\hline Temperature (T) & 6 & 19.9 & 13.7 & $<0.0001$ \\
Duration of leaf wetness (D) & 3 & 18.2 & 10.5 & $<0.0003$ \\
Experiment (E) & 9 & 12.9 & 8.9 & $<0.0001$ \\
T $\times$ D & 18 & 8.7 & 6.0 & 0.0002 \\
T $\times$ E & 14 & 2.2 & 1.5 & 0.2075 \\
D $\times$ E & 19 & 5.7 & 3.9 & 0.0024 \\
Error & 19 & 1.5 & $\ldots$ & $\ldots$ \\
\hline
\end{tabular}




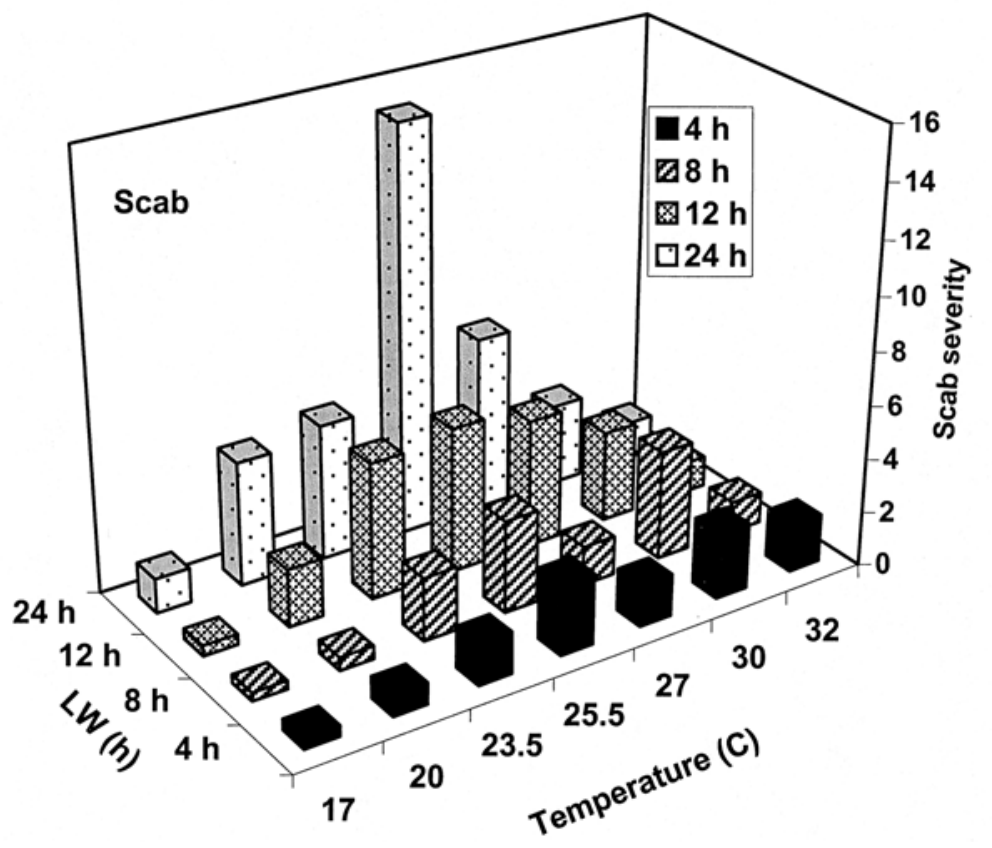

Fig. 1. Severity of scab on rough lemon leaves inoculated with conidia of Elsinoe fawcettii and maintained at different temperatures for various durations of leaf wetness (LW) in an incubator.

Table 3. Analysis of variance of the effect of temperature and duration of leaf wetness on the severity of melanose on grapefruit leaves inoculated in the laboratory with Diaporthe citri

\begin{tabular}{lrllc}
\hline Source & df & MS & $\boldsymbol{F}$ & \multicolumn{1}{c}{$\boldsymbol{P}$} \\
\hline Temperature (T) & 3 & 1.34 & 32.6 & 0.0001 \\
Duration (D) & 5 & 1.06 & 25.7 & $<0.0001$ \\
Experiment (E) & 2 & 1.24 & 30.0 & $<0.0001$ \\
T $\times$ D & 15 & 0.09 & 2.3 & 0.0116 \\
T $\times$ E & 31 & 0.14 & 3.5 & $<0.0001$ \\
D $\times$ E & 27 & 0.06 & 1.4 & 0.1152 \\
Error & 7 & 0.04 & $\ldots$ & $\ldots$ \\
\hline
\end{tabular}

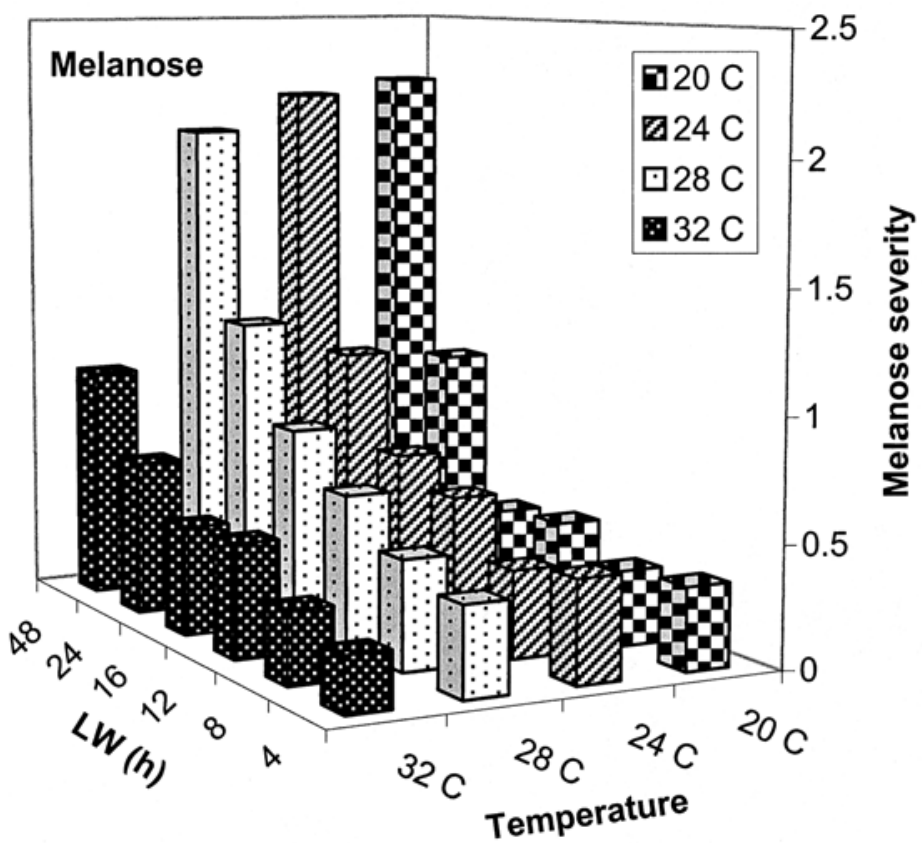

Fig. 2. Severity of melanose on grapefruit leaves inoculated with conidia of Diaporthe citri and maintained at different temperatures for various durations of leaf wetness (LW) in an incubator. inoculation with $E$. fawcettii was significantly affected by the temperature and duration of leaf wetness (Table 2). Low levels of infection were observed at all temperatures with only $4 \mathrm{~h}$ of leaf wetness (Fig. 1). The amount of infection increased with the duration of wetting, especially with temperatures from 23.5 to $27^{\circ} \mathrm{C}$, with maximum infection at $24 \mathrm{~h}$. Scab severity at $25.5^{\circ} \mathrm{C}$ and $24 \mathrm{~h}$ of leaf wetness duration was disproportionally high (Fig. 1). However, only two experiments were conducted at that temperature-wetness duration combination (Table 1), and scab was severe in both experiments. At $30^{\circ} \mathrm{C}$, some infection occurred, but severity was not great, even with $24 \mathrm{~h}$ of leaf wetness. Scab was insignificant at 17,20 , and $32^{\circ} \mathrm{C}$, even with 24 $\mathrm{h}$ of leaf wetness.

Differences among experiments were highly significant because the highest number of lesions per leaf varied from 4 to 19 . The temperature $\times$ leaf wetness duration interaction was significant (Table 2) due to different responses to leaf wetness duration at high and low temperatures compared with optimal temperatures (Fig. $1)$. The experiment $\times$ temperature interaction was not significant. The experiment $x$ leaf wetness duration interaction was highly significant (Table 2). Since all 10 experiments were conducted at the four leaf wetness durations, some differences occurred in response to experiments, but trends were usually similar.

Melanose. Temperature and leaf wetness duration were highly significant factors affecting the severity of symptoms with melanose (Table 3). Even with only $4 \mathrm{~h}$ of leaf wetness, some infection was observed at all temperatures evaluated (Fig. 2). Disease severity increased gradually with an increase in duration of leaf wetness up to $16 \mathrm{~h}$, but with durations of leaf wetness of $24 \mathrm{~h}$ or more, melanose severity was sharply higher. At $32^{\circ} \mathrm{C}$, even long durations did not result in high levels of infection. Experiment was a significant factor in the analysis (Table 3), because highest severity ratings varied from 1 to 4 in the different experiments. The experiment $x$ leaf wetness duration was not significant. The experiment $\times$ temperature interaction was highly significant (Table 3 ). Since all 13 experiments were conducted at the four temperatures, some differences occurred in response to the experiments, but trends were usually similar.

Field study: melanose. The relationship between total weekly rainfall and melanose severity was best described by a power function (Fig. 3A). Severity of melanose increased sharply with total weekly rainfall up to $20 \mathrm{~mm}$ per week. Although disease severity continued to increase with additional rainfall, the rate of increase was much less. Occasionally, melanose severity was high with relatively low amounts of rain. These data points represent weeks in which rains were followed by relatively 
long periods of leaf wetness. High rainfall totals were almost always associated with prolonged wetness durations and very severe melanose.

A polynomial equation best described the relationship between duration of leaf wetness and melanose severity (Fig. 3B). Most durations of leaf wetness of less than $80 \mathrm{~h}$ per week resulted in very low levels of melanose on the trap plants. Higher leaf wetness totals were associated with weeks of high rainfall.

The relationship between mean weekly temperature and melanose severity was best described by a polynomial equation (Fig. 3C). There was good agreement between field data and laboratory studies in that severity of melanose was seldom high when average weekly temperatures were less than $22^{\circ} \mathrm{C}$. When temperatures were higher than $22^{\circ} \mathrm{C}$, melanose was severe except in a few cases when rainfall and leaf wetness were low. In multiple regression analyses, rainfall explained the highest percentage of the variability. However, addition of temperature or leaf wetness duration to rainfall in the analysis did not greatly increase the proportion of the variability explained. Rainfall, leaf wetness, and temperature were highly related to each other. In Florida, springs are cool and dry, and summers are warm and moist. Thus, incorporation of all factors in a multiple regression analysis added little to understanding the relationship.

\section{DISCUSSION}

The optimum temperature range for infection and development of citrus scab was 23.5 to $27^{\circ} \mathrm{C}$. Results of previous studies $(1,10)$ were inconsistent, even though both of those studies were conducted with Florida isolates of E. fawcettii. Fawcett (1) observed no infection at temperatures above $23^{\circ} \mathrm{C}$, and Whiteside (10) found that the optimum temperature range for infection was 24 to $28^{\circ} \mathrm{C}$. Our results on the influence of leaf wetness duration on the severity of citrus scab confirm those of Whiteside (10). Low levels of infection occurred with only $4 \mathrm{~h}$ of wetness. In the optimum temperature range $\left(23.5\right.$ to $\left.27^{\circ} \mathrm{C}\right)$, wetness durations of $12 \mathrm{~h}$ usually maximized disease severity. However, at higher and lower temperatures, disease severity was relatively low even with $24 \mathrm{~h}$ of leaf wetness. In earlier studies (1), it is possible that maintaining leaf wetness at higher temperatures was difficult with the equipment available. Under field conditions in Florida, infection of young shoots by $E$. fawcettii may occur from first emergence of the shoots in late February or early March until the leaves are about one-half expanded. Fruit are susceptible from petal fall in late March for about 6 to 8 weeks. Rainfall in spring in Florida is usually low, and temperatures are typically below the optimum range for infection and development of scab. Nevertheless, with such short
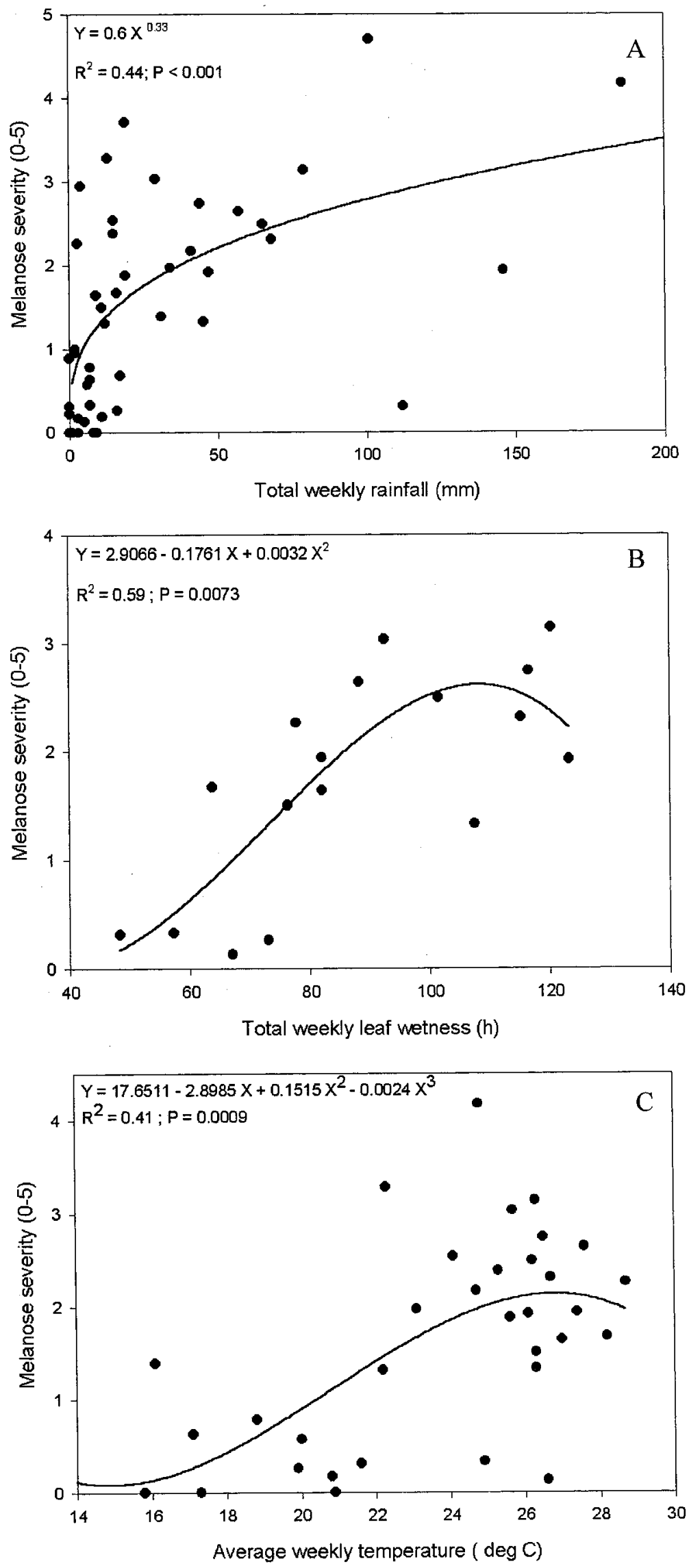

Fig. 3. Severity of melanose on grapefruit trap plants maintained in a grove for 1-week intervals in relation to: $\mathbf{A}$, total weekly rainfall, $\mathbf{B}$, total hours per week of leaf wetness, and $\mathbf{C}$, average weekly temperature. 
durations of leaf wetness needed for infection and occasional warm periods, disease may be severe. Scab development is also restricted by the limited dispersal of the pathogen by rain splash.

The optimum temperature range for leaf infection by $D$. citri was 24 to $28^{\circ} \mathrm{C}$ in our studies. Studies in Japan $(2,3,9)$ indicated that the duration of wetting needed to obtain infection was least when temperatures ranged from 24 to $28^{\circ} \mathrm{C}$. In those studies and ours, long durations of wetness were needed to get significant infection at lower or higher temperatures. In the optimum temperature range, low levels of infection were observed even at short durations of leaf wetness ( 4 to $8 \mathrm{~h}$ ). Even with 12 to 16 $\mathrm{h}$ of leaf wetness, only moderate levels of infection were observed. Maximum infection occurred only when leaf wetness duration was $24 \mathrm{~h}$ or longer.

In both the scab and melanose experiments, considerable differences were observed in disease severity among experiments. These differences were attributable to the age of the leaves inoculated. Especially with scab, but also with melanose, the age of the leaf greatly affects disease severity $(4,12)$. Leaf age within an experiment could be controlled adequately by plant and shoot selection, but it was difficult to standardize this factor among experiments.

Field studies with melanose supported the results of laboratory studies. Rain is needed before conidia begin to ooze from the pycnidia on dead twigs. However, weekly rainfall is not necessary if the duration of wetness is sufficiently long and temperatures are high. The durations of leaf wetness needed for infection by $D$. citri at temperatures below $22^{\circ} \mathrm{C}$ in the laboratory were longer than the times observed in the field. Infection periods producing serious disease are rare when temperatures are cool $(10,12)$. Results of these studies are consistent with previous work in Texas $(5,7)$. Melanose was most severe in June and early July, when temperature and rainfall were high. Rainfall in the spring in Florida and Texas is usually associated with fast-moving cold fronts. Thus, even when rainfall amounts are high, conditions are often cool and dry following the passage of cold fronts, and this may result in little infection by $D$. citri.

Fruit infection is far more important than leaf infection. Field observations indicate that fruit and leaf infection for scab and melanose occur under the same conditions. In groves with overhead irrigation, which is usually operated for about $12 \mathrm{~h}$, scab severity on fruit is greatly increased by watering; whereas melanose severity is not enhanced by overhead irrigation. Thus, leaf infection studies probably accurately reflect the conditions that promote development of scab and melanose in commercial citrus orchards.

\section{ACKNOWLEDGMENTS}

We greatly appreciate the technical assistance of A. J. Tesoriero and the advice on statistical analysis of R. C. Littell, Department of Statistics, University of Florida, Gainesville.

\section{LITERATURE CITED}

1. Fawcett, H. S. 1921. Some relations of temperature to growth and infection in the citrus scab fungus, Cladosporium citri. J. Agric. Res. 21:243-254.

2. Homma, Y., and Yamada, S. L. 1969. Factors influencing infection and development of cit- rus melanose caused by Diaporthe citri (Fawc.) Wolf. Bull Hortic. Res. Stn. Jpn. Ser. B9:85-96.

3. Kuramoto, T., and Yamada, S. L. 1975. The influence of environmental factors on citrus melanose infection due to Diaporthe citri. Bull. Fruit Tree Res. Stn. B2:75-86.

4. Timmer, L. W. 2000. Scab diseases. Pages 3132 in: Compendium of Citrus Diseases. L. W Timmer, S. M. Garnsey, and J. H. Graham, eds. American Phytopathological Society, St. Paul, MN.

5. Timmer, L. W., and Fucik, J. E. 1976. The relationship of rainfall distribution, fruit growth, and fungicide application to the incidence of melanose on grapefruit in Texas. Plant Dis. Rep. 60:565-568.

6. Timmer, L. W., Priest, M., Broadbent, P., and Tan, M.-K. 1996. Morphological and pathological characterization of species of Elsinoe causing scab diseases of citrus. Phytopathology 86:1032-1038.

7. Timmer, L. W., Reeve, R. J., and Fucik, J. E. 1979. The effect of rainfall, fruit growth, and fungicide application on melanose severity on Texas grapefruit, 1976-1978. J. Rio Grande Valley Hortic. Soc. 33:49-53.

8. Timmer, L. W., and Zitko, S. E. 1996. Evaluation of copper fungicides and rates of metallic copper for control of melanose on grapefruit in Florida. Plant Dis. 80:166-169.

9. Ushiyama, K. 1976. Studies on citrus melanose disease of satsumas. IV. Observations on the germination and penetration of spores of the casual fungus Diaporthe citri and on affected tissues. Bull. Kanagawa Hortic. Exp. Stn. 23:11-18.

10. Whiteside, J. O. 1975. Biological characteris tics of Elsinoe fawcettii pertaining to the epidemiology of sour orange scab. Phytopathology 65:1170-1177.

11. Whiteside, J. O. 1977. Sites of action of fungicides in the control of citrus melanose. Phytopathology 67:1067-1072.

12. Whiteside, J. O. 2000. Melanose. Pages 28-29 in: Compendium of Citrus Diseases. L. W. Timmer, S. M. Garnsey, and J. H. Graham, eds. American Phytopathological Society, St. Paul, MN. 